\title{
THE IMPLEMENTATION OF LIFE CYCLE ANALYSIS TOOLS IN ENVIRONMENTAL EDUCATION
}

\author{
Samir B. Billatos, Nadia A. Basaly \\ The University of Texas at Brownsville \\ Department of Engineering Technology \\ Brownsville, TX 78520
}

\begin{abstract}
Post manufacturing life cycle analysis, e.g. design for serviceability and design for retirement, are surfacing in very structured methodologies and tools, primarily software. These methodologies and tools not only impact environmental friendliness, but also impact our economical efficiency and production quality. It is the objective of this paper to present these methodologies and discuss their incorporation in an educational program. The authors feel that environmental awareness should start early in our educational system. The paper describes how life cycle methodologies and tools can be implemented in a mechanical design for the environment course. In addition, the paper shows how searching the Internet has led to the discovery and use of software for post manufacturing life cycle analysis. This software and others could easily be used in the classroom to evaluate common products (e.g., household appliances) and industrial case studies.
\end{abstract}

\section{INTRODUCTION}

The product life cycle has been extensively examined through engineering and design. If a product can be thoroughly designed in the conceptual design stage, satisfying the numerous design for the environment (DFE) guidelines [1], environmental impact and production cost can be greatly reduced. Theories in life cycle engineering are being developed to minimize product cost and environmental impact, and maximize product quality. In reality, these goals have to be balanced to form a well-rounded design.

Manufacturing life cycle analysis is mature, with very developed design for manufacturing (DFM) and design for assembly (DFA) strategies. However, design for serviceability (DFS), design for retirement (DFR) and life-cycle assembly tools, the main components of post manufacturing life cycle analysis, are beginning to surface in structured methodologies. Some of these methodologies, researched for this paper, aid in all the stages of life cycle analysis. Some address the process of disassembly, which is present in both DFS and DFR. Some look specifically at the environmental impact made by the products' materials. In this paper, DFS and DFR will be examined and evaluated for their significance in life cycle analysis. Their importance and impact on the environment must be taught in the classroom to prepare a new generation of environmentally friendly engineers. This paper introduces these 
methodologies and outlines a new course "mechanical design for the environment", that could be used to teach these methodologies.

\section{PRODUCT LIFE CYCLE}

The path taken by a product's life is known as its life cycle. This cycle generally follows the product's creation, use, retirement, etc. Products, as a whole, or components of these products, can be reused and recycled several times before disposal. Since all things have a limited life, products' life cycles can be thoroughly mapped.

Researchers view product life cycles in several different stages. Alting [2] distinguishes a life cycle as need recognition, design development, production, distribution, use and disposal. Zust and Wagner [3] distinguish life cycle as product definition, development, marketing, manufacturing, and usage. It should be noted here that all products would not follow the proposed cycle stages. For instance, made to order products will not need a product marketing stage.

In terms of environmental friendliness, product life cycle can be optimized using life cycle engineering and design. Figure 1 is one example of a product' life cycle.
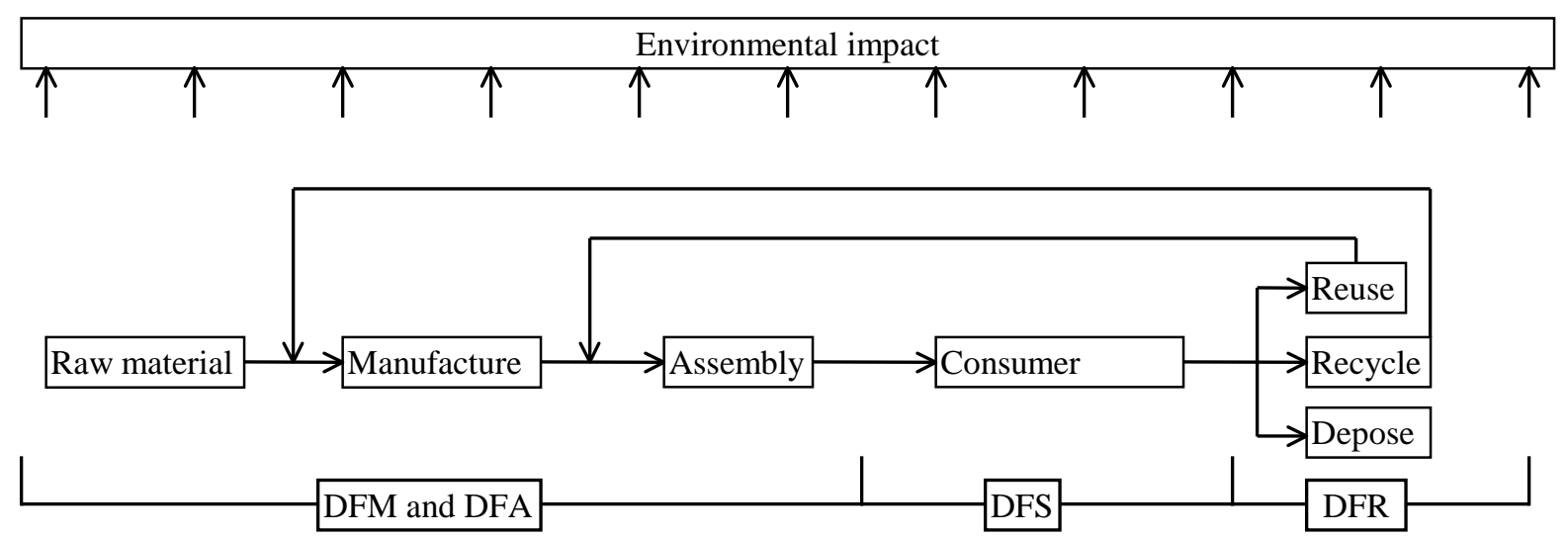

Figure 1 - Product and Component Life Cycle

Several goals exist for life cycle engineering. In the example of Figure 1, one goal is to maximize reuse and recycling stages through design to reduce environmental impact. Another goal is to minimize environmental impact for every stage. These goals are satisfied through the known and practiced DFX analysis methods (Design for X, where X implies a specific form of optimization, such as zero defects or automated assembly. It simply refers to any of the design strategies such as design for manufacturing, design for assembly, etc.). Design for Manufacturing and Assembly (DFMA), Design for Serviceability (DFS), and Design for Retirement (DFR) are three major areas of these methods. 


\section{POST MANUFACTURING LIFE CYCLE ANALYSIS}

Post manufacturing life cycle analysis addresses DFS and DFR. Details of these methodologies and tools are discussed below.

\subsection{Design for Serviceability}

If a design did not take DFS into consideration, it would tend to have many serviceability problems. These types of failures would lead to great consumer expense and a bad product reputation both for quality and for the environment.

DFS, includes design for disassembly, design for maintainability and design for reliability [4]. Design for disassembly is similar to DFA. Several of its methodologies use the axiomatic theory [5]: reduce the number of parts and processes, while maintaining the functionality of the design. Design for maintainability can be based on the following definition by Moss [6]: "maintainability is that element of product design concerned with assuring that ability of the product to perform satisfactorily can be sustained throughout its intended useful life span with minimum expenditure of money and effort". Minimizing the amount of maintenance needed by a design in the conceptual design stage can satisfy the goals of design for maintainability and make the product reliable to the consumer.

Design for Reliability helps assure the reliability (the persistent performance) of the part before committing the design to fabrication. This process helps to accomplish a successful part development with a single pass at design fabrication and circuit evaluation. The reduction in the number of passes reduces the time-to-market and the cost of development. Including reliability optimization during design also helps assure that reliability is not an afterthought, just something extra thrown in at the end; but rather is an integral part of the product. Making reliability part of the design should also enhance the reliability of the final product, reducing downtime in the field, and increasing the time between failures.

\subsection{Design for Retirement}

The concept of product retirement is one that most consumers do not think about. Failure to take DFR into consideration tends to maximize waste thus maximizing environmental impact.

DFR, includes design for recycling, design for reuse, and design for disposal. In order to design for recycling a designer must take into account the following five concepts of recycling [7]:

- Retrieval - Transportation, storage and handling of the material.

- Separation - The ease of disassembly.

- Identification - The ease of identifying the type of material

- Reprocessing - Methods used in processing of the material 
- Remarketing - Reinduction of the material to the market.

Design for reuse can eliminate the cost and environmental impact of recycling. Material disposal should be avoided at all times. Disposal has the greatest effect on environmental impact. If a material cannot be recycled or reused it probably means that it is very difficult to break down and decompose.

\section{METHODOLOGIES AND TOOLS}

\subsection{Life-cycle Assembly Software}

Searching the Internet helped us to find an interesting program called LASeR 1.0 [8]. The program, developed by Stanford University, is a windows-based software that evaluates design for assembly, serviceability, and retirement of mechanical designs. Its creators are part of the Ohio State University's Life Cycle Engineering Group. A shareware version and its User's Manual are currently available on the Internet. The methodology of the software is summarized in Figure 2.

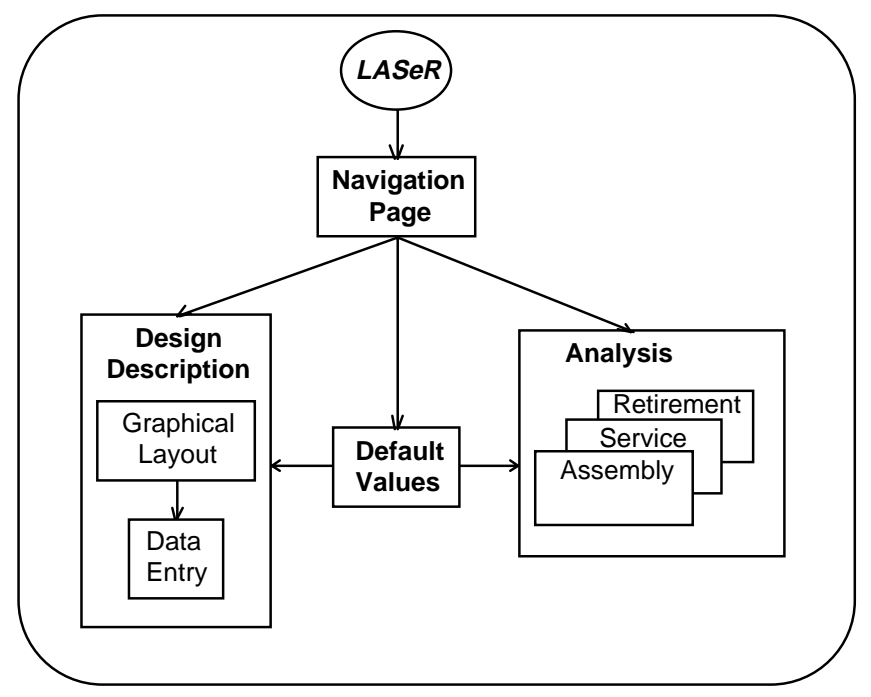

Figure 2 - LASeR 1.0 System Methodology

First, the user defines a description of a mechanical design. Several parameters are defined including structural design, cost, types of labor and material data.

The "linker" [9] scheme is then used to define the structural layout. In this scheme all components and/or subassemblies are presented in a hierarchical network with information on how they are linked to one another. An example of an automatic coffee maker assembly is shown in Figure 3. Each node of the network is defined as a component, subassembly, fastener, or process. The links of the network are defined to perform the task of covering, attaching to, 
connecting to, engaging, and supporting. While the definition of the network node is very straight forward, the definition of the network link is not. Detailed information on the link definitions is located in LASeR's User Manual. These link definitions are the real drivers for estimation of disassembly times. Additional easy to use menus are also available to input cost and material data.

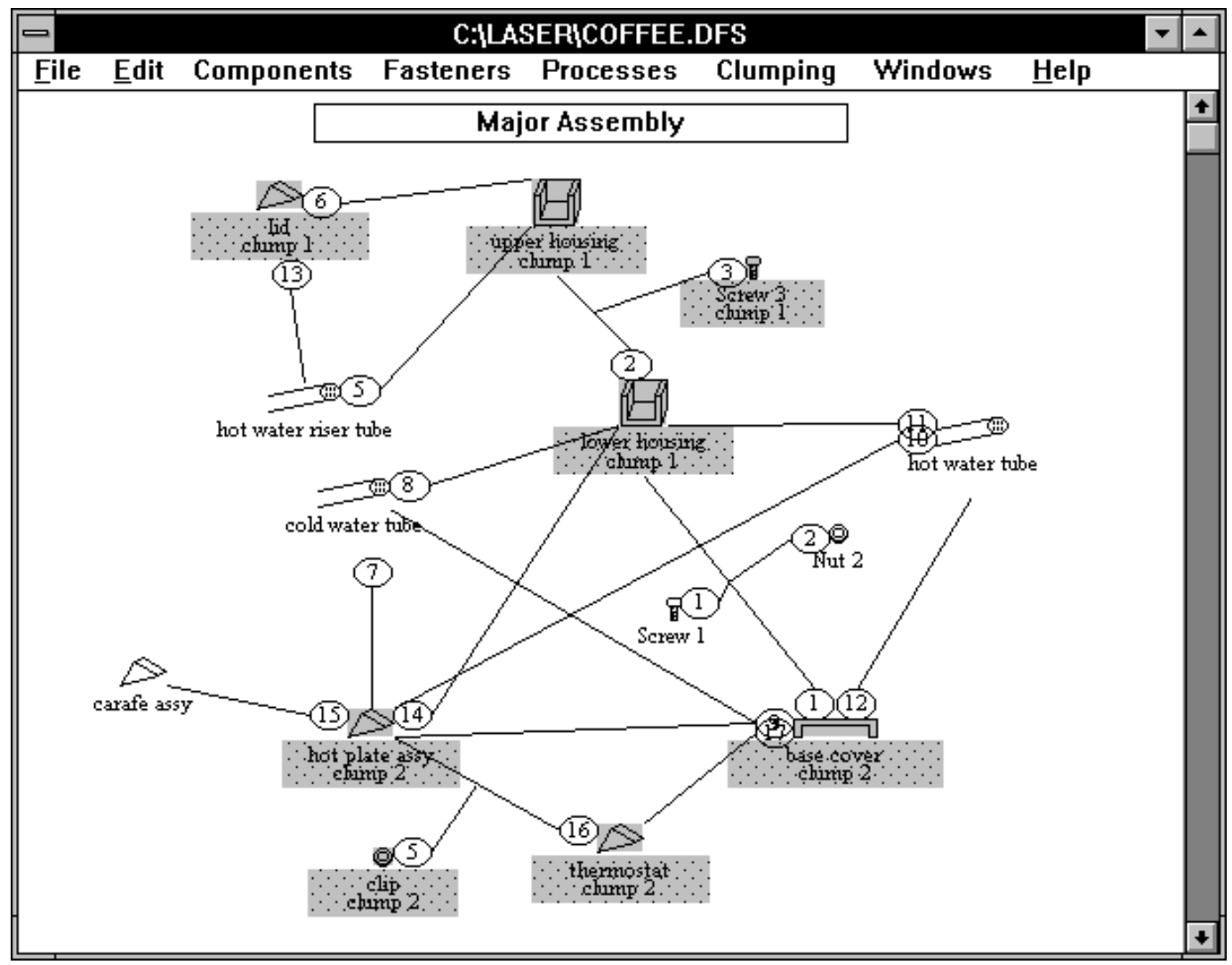

Figure 3 - Layout design for an automatic coffee maker

Design for serviceability begins with selecting certain labor operations. Operations chosen include tightening/connecting/lubricating, adjusting/aligning, replacing, repairing, and overhauling. Times and life cycle frequencies are then defined. Evaluation of serviceability results in the associated labor steps and service costs. Since the mechanical design is defined with the "linker", all the steps taken to perform an operation are known and calculated, then shown to the user.

Design for retirement begins with selecting groups of compatible components, or "clumps". These clumps are defined as parts with similar functions and material. Upon analysis, the tool calculates reprocessing costs associated with the given clumps. 


\subsection{Reverse Fishbone disassembly Methodology}

This methodology uses a graphical layout known as a Reverse Fishbone Diagram [8]. The graphical layout usually represents subassemblies of a total product design. Helpful in both DFS and DFR, the diagram is used to model the disassembly sequence of a mechanical design.

A detailed description of the diagram (fishbone diagram) is given in reference 8 . It is made of levels, nodes, and endnodes. The levels indicate the number of disassembly stations. Nodes indicate the actual disassembly process. The end nodes indicate components that are reused or recycled upon retirement.

At first glance, the fishbone diagram can tell the designer much about the disassembly. The size and shape of the tree (fishbone diagram) prefigures the complexity of the disassembly. Generally, a small tree tells the designer the mechanical design is a good candidate for simple disassembly. A larger tree, being more complex, shows a candidate design for difficult disassembly. Taking designers through each step of the disassembly sequence aids in identifying difficulty and faults during the product's conceptual design stage.

\subsection{The Recyclability Map Tool}

The Recyclability Map, shown in Figure 4 [8], aids in material selection for a design to enhance DFR. Different from the fishbone diagram, this tool graphically represents the product as a whole.

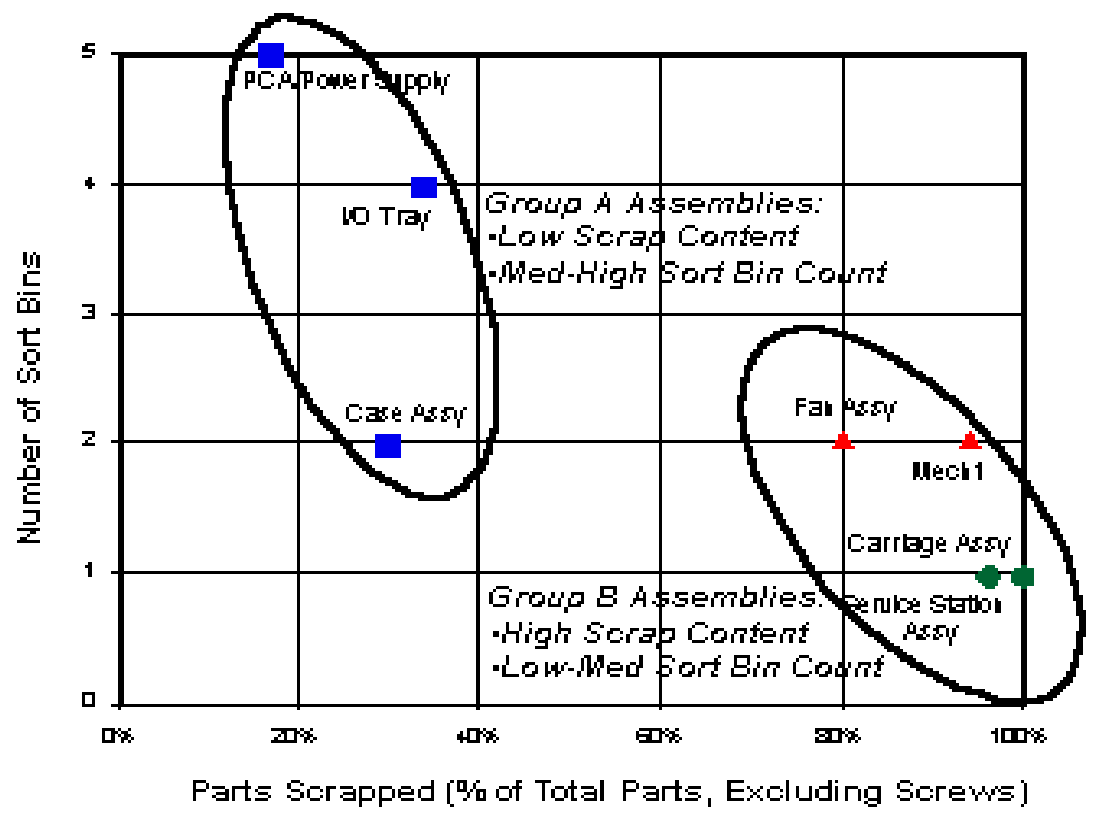

Figure 4 - Recyclability Map [8]

The Recyclability Map is defined as the number of sort bins versus the percentage of parts scraped in the subassembly. The number of sort bins is similar to the number of levels in the 
fishbone diagram. The Recyclability Map is constructed by plotting each subassembly's parameters. At a glance, the Recyclability Map can tell the designer much about the recyclability of the design. Generally a fewer number of sort bins exhibits a good candidate for disassembly. So subassemblies located in the lower left-hand corner of the map are good candidate for recyclability. When other subassemblies are good candidates for redesign.

\subsection{Environmental Impact Factors Analysis}

The Environmental Impact and Factors Analysis (EIFA) [9] is one of the excellent tools of life cycle analysis. It enhances DFR, DFS and all DFX criteria. It is a windows based spreadsheet tool that examines potential environmental hazards posed by components of a design. EIFA is analogous to Failure Modes and Effects Analysis, but has been restricted to address environmental issues, not component failure. The EIFA methodology was developed at Stanford University and it is currently available on the Internet.

The methodology begins with a component identification. Components can be clumped into groups such as in the LASeR recyclability methodology. Then, for each component or clump several items are defined. These items include clump function, factors of environmental impact, factors of reusability, and factors of redesign. Upon evaluation potential scores of redesign are presented. The higher the potential score the greater the opportunity exists in improving the design for environmental friendliness.

After acquiring the results the designer should first focus design improvement on a particular component or clump. In this way EIFA identifies the best approach whether it is reusability or recycleability. Another way to redesign is to improve globally. The designer should pick several components or clumps, with the highest probability of improvement. This will ensure that improvement will address the designer's environmental concerns.

\section{IMPLEMENTATION IN CURRICULUM}

Most of Mechanical Engineering curricula offer standard mechanical engineering courses. They don't introduce students to other important topics such as environmental engineering. We are therefore recommending the implementation of a Mechanical Design for the Environment course as an advanced undergraduate elective course or a graduate course.

The course will serve as an introduction to green technology and design for the environment. With this objective in mind, the course is divided into two parts. Topics of each part are shown in Table 1 below.

\section{Table 1: Course Outlines}

\begin{tabular}{|ll|l|}
\hline \multicolumn{1}{|c|}{ Part I } & \multicolumn{1}{c|}{ Part II } \\
\hline 1. What is Environmental Engineering? & 7. & The Manufacturing Process Design Rules. \\
2. Green Engineering and Environmentally & 8. Axiomatic Design. \\
\hline
\end{tabular}




\begin{tabular}{|c|c|}
\hline $\begin{array}{ll}\text { 3. } & \text { Con } \\
\text { 4. } & \text { Reg } \\
\text { 5. } & \text { Env }\end{array}$ & $\begin{array}{l}\text { (Hitachi, Taguchi, etc.). } \\
\text { lysis. } \\
\text { uality. } \\
\text { atation of Green Design a }\end{array}$ \\
\hline
\end{tabular}

The first part will introduce the problems the world faces today on the road to environmentally safe products. First, the basic subject of green engineering will be introduced and defined. This subject has a broad interdisciplinary scope and is applicable to every phase of design and manufacturing. The basic problems and magnitude of waste and the need to revise current design practices will then be introduced. To emphasize team work concepts, students will be grouped into teams. These teams will have a major task of using the Internet and other search procedures (library, etc.) to summarize the monumental body of information on past examples of environmental damage, the growing body of regulations, and the newly emerging ethic of stewardship by some more progressive members of industry.

Students will then be introduced to the methods of solving environmental problems. These methods will be presented in a consistent format of Design for X philosophy (where, as stated earlier, $\mathrm{X}$ implies a specific form of optimization, and extends to a thorough treatment of several important categories of optimization). In these topics, guidelines to designing for the environment and an in depth treatment of recycling issues, especially with respect to plastics, will be introduced.

The second part will provide a number of examples and case studies from industry. The subjects of designing for assembly and disassembly from the mechanical side will be presented. Products familiar to students such as computers, household appliances, hair dryers, phones, etc. will be used for hands-on experience with these topics. Students will dissect these products to understand their components and functions and the type of material of each component. They would make recommendations on improving these products by selecting different material and/or minimizing the number of components needed to make the product. Simple axioms and general outlines of manufacturing processes from an environmental perspective, and identification of a variety of new alternatives that waste less material and result in substantially less pollution will be discussed. Knowledge of the adverse environmental impacts of various processes in the design stage is an essential part of such an environmentally conscious engineering course.

Finally, some analysis and design tools for continuous improvement of quality products and processes will be presented. Students will exercise the practical application of designing for quality of environmentally safe devices. They will also learn the decision making tools which are essential to accurate and creative design synthesis. These methods will become the primary workhorses of environmentally conscious engineering, for they provide a much-needed degree of order to the expanded and complex scope of environmentally conscious design. 


\section{CONCLUSIONS AND RECOMMENDATIONS}

New methodologies are rapidly forming to satisfy design for the environment. Methodologies available through software make the job of the designer simpler. To the average consumer, the purchase of product does not involve thinking about the product's lifetime existence. People who are not engineers should not have to think like engineers. It is the engineers' responsibility to design for the environment to make sure the product is environmentally sound. To achieve this goal, the paper has addressed the development of a mechanical design for the environment course that implements these methodologies to prepare new generations for environmental friendliness.

\section{REFERENCES}

1. Billatos, S.B. and Basaly, N.A. Green Technology and Design for the Environment, Taylor \& Francis, 1997.

2. Alting, L., "Editorial: The New Milieu of Manufacturing", Journal of Manufacturing Systems, Vol. 11, No. 2, pp. 1, 1992.

3. Zust, R., and Wagner, R., "Approach to the Identification and Quantification of Environmental Effect during Product Life", Annals of the CIRP, vol. 41(1), pp. 473-476, 1992.

4. Ishii, K., and Mukherjee, S., "Post Manufacturing Issues in Life Cycle Design", ASME: Design for Manufacture, vol. 51, 1992.

5. Suh, N. P. The Principles of Design, Oxford University Press, 1990.

6. Moss, M. A., "Designing for Minimal Maintenance Expense", Marcel Dekker Inc, New York, 1985.

7. Life cycle Engineering Group, Stanford University, "LASeR 1.0: Life-cycle Assembly, Service and Recycling Software and User's Manual", 1994.

8. Ishii, K., "Design for Recycle Modularity", http://mml-mac-9.stanford.edu/MMLWeb Doc.stanford.edu/MMLWebDocs/research/projects/summary/dfe/dfe.html, 1996.

9. "EIFA", http:/dfe.stanford.edu/eifa.html, 1996.

\section{BIOGRAPHICAL SKETCHES}

Dr. Samir B. Billatos is a Professor at the University of Texas Brownsville. He received his M.S. and Ph.D. degrees from Washington State University. His prior experience includes teaching and research in the Design and Manufacturing areas at the University of Connecticut, New Jersey Institute of Technology, University of Idaho, Hewlett-Packard Company, University of Helwan (Egypt) and Washington State University. He published more than 60 journal and conference papers, edited four ASME proceedings and wrote a new book Green Technology and Design for the Environment that was published by Taylor \& Francis in 1997. He organized and chaired a number of symposiums sponsored by ASME on practical applications of Design for the environment, design for manufacturing and assembly, and concurrent engineering. 
Dr. Nadia A. Basaly is an Assistant Professor at the University of Texas Brownsville. She received her M.S. and Ph.D. degrees from the University of Connecticut. Her prior experience includes teaching and research in the Manufacturing areas at the University of Connecticut, New Jersey Institute of Technology, Rutgers University, Stevens Institute of Technology and University of New Haven. She published a number of papers and co-authored a new book Green Technology and Design for the Environment that was published by Taylor \& Francis in 1997. 